\title{
Interstitial Pneumonitis after Treatment with Bevacizumab and Pegylated Liposomal Doxorubicin in a Patient with Metastatic Breast Cancer
}

\author{
Jens Huober ${ }^{\mathrm{a}}$ Otto Schoch ${ }^{\mathrm{b}}$ Arnoud Templeton ${ }^{\mathrm{a}}$ Christian Spirig $^{\mathrm{a}}$ Beat Thürlimann ${ }^{\mathrm{a}}$

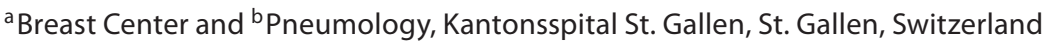

We report on a patient with metastatic breast cancer in whom interstitial pneumonitis developed after treatment with bevacizumab in combination with pegylated liposomal doxorubicin (PLD). Reexposure to PLD after recovery was without any pulmonary side effects.

A 53-year-old woman presented with symptomatic histologically proven diffuse metastatic infiltration of the stomach as the only site of disease 5 years after primary diagnosis of lobular breast cancer. Treatment with PLD (Caelyx ${ }^{\circledR}$ ) $20 \mathrm{mg} /$ $\mathrm{m}^{2}$ in combination with bevacizumab (Avastin $^{\circledR}$ ) $10 \mathrm{mg} / \mathrm{kg}$ every 2 weeks was started in a study protocol.

Treatment was initially well tolerated and abdominal symptoms disappeared completely. After 3 courses of treatment, the patient developed persistent cough and shortness of breath. High-resolution CT scan showed ground glass opacities compatible with interstitial pneumonitis. Analysis of arterial blood gases confirmed the presence of hypoxemia. As history and diagnostic work-up could rule out other causes of interstitial pneumonitis (infections, tumor progression and autoimmune disorders), drug-induced interstitial pneumonitis was regarded the most likely cause of respiratory symptoms. All antineoplastic drugs were discontinued. With prednisone $50 \mathrm{mg}$ daily, tapered off over 6 weeks, symptoms resolved promptly, and lung function tests and CT scan after 6 weeks documented improvement (table 1). We assumed bevacizumab more likely causative for drug-induced pneumonitis than PLD as there are much more safety data available for PLD without clear evidence of interstitial pneumonitis related to PLD [1]. Thus, we decided to reinitiate PLD alone after a 3-month treatment holiday. No pulmonary side effects were noted, suggesting bevacizumab being the cause of interstitial pneumonitis. Pulmonary complications observed so far with bevacizumab are hemorrhage and hemoptysis, mainly observed in lung cancer patients and more commonly seen in patients with squamous cell carcinoma of the lung than in those with nonsquamous histology [2]. Only lately, a first description of interstitial pneumonitis in a patient treated with the combination of bevacizumab and docetaxel has been reported [3].

The pathogenesis of antineoplastic drug-induced lung injury is poorly understood. Direct injury to pneumocytes or the alveolar capillary endothelium (chemical alveolitis) may contribute to chemotherapy-induced lung injury. Monoclonal antibodies like rituximab and trastuzumab have also been associated with interstitial pneumonitis. Cytokine release and inability of pneumocytes to respond to lung injury through HER2 inhibition have been postulated as mechanisms in these cases [4]. Recently, abnormal vascular endothelial growth factor expression has been shown in patients with interstitial pneumonitis [5]. We hypothesize that by impairing the alveolar repair mechanism through antiangiogenic mechanisms, lung injury may be potentiated by bevacizumab and may facilitate the development of pneumonitis as observed in our patient.

Here, we report a case of interstitial pneumonitis most likely associated with the drug bevacizumab. As bevacizumab was given in combination with chemotherapy, the causative role of bevacizumab is not definitely proven. However, since the patient's re-exposure to PLD was without any pulmonary symptoms, pneumonitis was most likely caused or potentiated by bevacizumab. Physicians should thus be aware of this rare but serious side effect when prescribing this drug.

\section{KARGER}

Fax +4161306 1234 E-Mail karger@karger.ch www.karger.com www.karger.com/che
Prof. Dr. Jens Huobe

Brustzentrum

Kantonsspital St. Gallen

CH-9007 St. Gallen (Switzerland)

Tel. +41 7149411 77, Fax +41 7149463 68, E-Mail jens.huober@kssg.ch 
Table 1. Symptoms, diagnostic procedures and results

\begin{tabular}{|c|c|c|}
\hline & At diagnosis & At follow-up \\
\hline Clinical signs and symptoms & cough and dyspnea CTC grade III & resolved \\
\hline CT of the chest & $\begin{array}{l}\text { ground glass opacities in several areas } \\
\text { of the lung (high-resolution CT) }\end{array}$ & normal \\
\hline Bronchoscopy with bronchoalveolar lavage & $\begin{array}{l}\text { total cell count } 119 \times 10^{6} \\
\text { lymphocytes } 49 \% \\
\text { macrophages } 48 \% \\
\text { neutrophilic granulocytes } 1 \% \\
\text { eosinophilic granulocytes } 2 \% \\
\text { no malignant cells } \\
\text { no growth of fungi, bacteriae including acid-fast bacilli }\end{array}$ & \\
\hline Blood gas analysis on room air at rest & $\begin{array}{l}\mathrm{pH} 7.44 \\
\mathrm{pCO}_{2} 35.6 \mathrm{~mm} \mathrm{Hg} \\
\mathrm{pO}_{2} 50.1 \mathrm{~mm} \mathrm{Hg} \\
\text { alveolo-arterial oxygen gradient } 48.4 \mathrm{~mm} \mathrm{Hg} \\
\text { oxygen saturation } 85 \%\end{array}$ & \\
\hline Oxygen saturation by pulse oximetry at rest & oxygen saturation $89 \%$ & oxygen saturation $95 \%$ \\
\hline \multicolumn{3}{|l|}{ Lung function tests } \\
\hline Forced vital capacity & 3.00 liters (95\% predicted) & 3.50 liters ( $111 \%$ predicted) \\
\hline Forced expiratory volume & 2.56 liters (95\% predicted) & 2.74 liters (102\% predicted) \\
\hline Diffusing capacity for carbon monoxide & $4.5 \mathrm{mmol} / \mathrm{min} / \mathrm{kPa}$ ( $54 \%$ predicted $)$ & $\begin{array}{l}6.9 \mathrm{mmol} / \mathrm{min} / \mathrm{kPa} \\
(82 \% \mathrm{predicted})\end{array}$ \\
\hline
\end{tabular}

$\mathrm{CTC}=$ Common terminology criteria for adverse events, version 3.0.

References
Vahid B, Marik PE: Pulmonary complications of novel antineoplastic agents for solid tumors. Chest 2008;133:528-538.

2 Di Costanzo F, Mazzoni F, Mela MM, et al: Bevacizumab in non-small cell lung cancer. Drugs 2008;68:737-746.

-3 Prat A, Martinez P, Serrano C, et al: Acute lung injury associated with docetaxel and bevacizumab. Clin Oncol 2007;19:803-805.
4 Vahid B, Mehrota A: Trastuzumab (Herceptin)-associated lung injury. Respirology 2006;11:655-658.

5 Navarro C, Ruiz V, Gaxiola M, Carrillo G, et al: Angiogenesis in hypersensitivity pneumonitis. Arch Physiol Biochem 2003;111: 365-368. 